\title{
OS PROGRAMAS DE MESTRADO EM ECONOMIA NO BRASIL SÃO PLURALISTAS? - DISCIPLINAS
} OBRIGATÓRIAS

Are Brazilian economic master's programs pluralist? - Mandatory lectures

Felipe Romeira Pereira

Universidade Federal do ABC, Santo André-SP, Brasil

felipe.rp19@gmail.com

\begin{abstract}
RESUMO
Este trabalho analisa os programas de mestrado em economia no Brasil e classifica estes em ortodoxo, pluralistaortodoxo, pluralista, pluralista-heterodoxo ou heterodoxo. Há uma explicação do porquê utilizar cinco categorias ao invés da tríade comum ortodoxo, pluralista, heterodoxo no primeiro artigo. Para realizar essa classificação, analisa cada disciplina obrigatória que o programa ensina. Cataloga esses documentos analisados em uma das três categorias da tríade comum e então cataloga o programa. No total foram 162 ementas analisadas pertencentes a 56 programas de mestrado. Este trabalho não analisa ementas de matemática e econometria pois entende que não é possível classificar esses cursos em uma das categorias da tríade comum. Para classificar as ementas há uma lista de quais assuntos são considerados heterodoxos e quais ortodoxos nas duas disciplinas mais comuns, macroeconomia e microeconomia. Por fim, o trabalho analisa o estudo de outros acadêmicos que fizeram o mesmo trabalho de catalogar os programas brasileiros e encontra resultados diferentes dado que a metodologia de classificação utilizada foi diferente. Nas considerações finais sugere motivos para as diferenças encontradas e levanta questões para trabalhos futuros.
\end{abstract}

PALAVRAS-CHAVE: Pluralismo; Economia no Brasil; Programas de Mestrado em Economia.

\begin{abstract}
This study analyses Brazilian economics master's programs and catalogues them into orthodox, pluralist-orthodox, pluralist, pluralist-heterodox or heterodox programs. There is an explanation on why using five categories instead of the three classical expected (orthodox, pluralist and heterodox). To do that, analyses every mandatory lecture that the program teaches. Catalogues the documents in one of the three classical classifications and then catalogues the programs. In total there are 162 course curriculum analysis. This paper does not analyze mathematics and econometrics course curriculums as it believes it is not possible to classify these courses on the three classical classifications. To classify the courses there is a list of which subjects would be counted as heterodox and which subjects as orthodox on the most popular lectures (macroeconomics and microeconomics). This study also analyses the paper of other academics that did this same work of cataloguing every Brazilian program into orthodox, heterodox or pluralist, it finds different results as the methodology for classifying is different in each study. At the end it suggests reasons for the differences and rise questions for future studies. KEYWORDS: Pluralism; Brazilian Economics; Economics master's programs.
\end{abstract}

Classificação JEL: A23; B41; 123

Recebido em: 10-11-2020. Aceito em: 15-06-2021. 


\section{INTRODUÇÃO}

O objetivo deste estudo é analisar o currículo das disciplinas obrigatórias dos programas de mestrado em economia no Brasil e classificar o material analisado e, portanto, os programas em ortodoxos, pluralista-ortodoxos, pluralistas, pluralistasheterodoxos ou heterodoxos.

O trabalho está interessado neste tópico por acreditar que o tipo de educação em economia que os alunos estão expostos nas salas de aula é um fator relevante para formar um economista que acredite, concorde, goste ou desgoste das diferentes vertentes da disciplina econômica.

O trabalho se preocupa com a possibilidade de os alunos não estarem expostos ao "outro jeito" de pensar a economia (em uma dualidade ortodoxia/heterodoxia) e, portanto, ficarem desmotivados a continuar os estudos por não estarem aprendendo algo que não encaixa com o seu entendimento da realidade.

Pode-se argumentar que um bom aluno deveria então estudar "o outro jeito" da economia em seu tempo livre, fora das salas de aula. O problema com este argumento é que um aluno pode ter muitas outras responsabilidades, que incluem contas a pagar e lazer a ser vivido. Esse aluno pode estar interessado em conhecer formas diferentes de pensar a economia, mas como não há tempo o suficiente para fazer e estudar tudo, o aluno decide então se matricular em um programa para conhecer mais sobre a ciência econômica. No entanto, se ele não é exposto ao "outro jeito" de pensar a economia, talvez ele nunca dê uma chance para esse "outro jeito" e então talvez pense que não há relevância no trabalho do outro, já que não compreende.

A razão para estudar apenas as disciplinas obrigatórias e não todas as disciplinas ofertadas é a intenção de verificar se há uma preocupação do programa em mostrar aos alunos as diferentes formas de pensar da ciência econômica, pois se houver esta preocupação, essas formas diferentes de pensar estariam disponíveis através das disciplinas obrigatórias. Assim, todo aluno de mestrado estaria exposto ao menos um pouco ao "outro jeito" de pensar, e se eles quiserem se especializar em apenas um jeito, então podem escolher as disciplinas que mais Ihe agradam entre as disciplinas não obrigatórias.

O trabalho não analisa o nível de graduação pois entende que em sua maioria compõe manuais tradicionais. Também não analisa o nível de doutorado pois assume que os alunos deste nível podem já ter um entendimento maior da ciência econômica e suas 
variações. Também, por haver mais tempo para estudo no programa de doutorado, já que mantem mais anos de relacionamento com o aluno.

Com isso dito, é necessário explicar por que se tem cinco classificações ao invés de três (ortodoxo, heterodoxo, pluralista). Basicamente porque alguns programas de mestrado têm somente três disciplinas obrigatórias, e uma delas sendo econometria (que não é classificada - explicação abaixo) então o programa pode ter uma disciplina de microeconomia pluralista e uma disciplina de macroeconomia que é ortodoxa. Então como classificar esse programa? Não pode ser ortodoxo, nem pluralista puramente. Então o programa é pluralista-ortodoxo.

Este artigo está separado em duas seções. Esta que se chama Introdução (1) e explica de forma breve a que se propõe o artigo, e sua subseção intitulada Heterodoxia, Ortodoxia e Pluralismo Econômico (1.1) onde o artigo apresenta definições destes termos e reflexões acerca deles. A segunda seção é chamada de AS DISCIPLINAS OBRIGATÓRIAS DOS PROGRAMAS DE MESTRADO EM ECONOMIA NO BRASIL (2) que tem como objetivo analisar os 56 programas disponíveis hoje no Brasil, e classificá-los em ortodoxos, pluralistas ou heterodoxos, no que diz respeito às suas disciplinas obrigatórias. Esta seção (2) contempla duas subseções, a primeira sendo intitulada Metodologia (2.1) onde se explica o método de classificação de cada centro de pesquisa baseado nas disciplinas obrigatórias, e em específico explicam-se como são classificadas as disciplinas de Microeconomia (2.1.1) e Macroeconomia (2.1.2) que são obrigatórias a todos os programas brasileiros. A segunda seção é intitulada Dados (2.2) e nela consta a relação completa de todos os programas analisados, as classificações das disciplinas analisadas, e a classificação final do programa, baseado nas disciplinas analisadas. Também constam exemplos singelos de instituições que se divulgam como plurais em seu website. O artigo encerra com suas Considerações Finais (2.3) e recomendações para trabalhos futuros. Ao fim, constam as Referências utilizadas no trabalho.

\subsection{Heterodoxia, Ortodoxia e Pluralismo Econômico.}

O objetivo desta seção é apresentar definições dos termos do título e reflexões acerca destes. Dequech (2007) é breve em seu comentário sobre o que define a economia ortodoxa e coloca que a mesma pode ser classificada como a escola de pensamento dominante. Dequech (2007) também deixa claro que o que é ortodoxia ou heterodoxia muda no tempo, é por este motivo que na seção dois constam exemplos de disciplinas ortodoxas e heterodoxas bem como os livros que referenciam essas disciplinas. 
Para comentar a economia heterodoxa, Dequech (2007) elabora mais. Coloca que é possível definir a heterodoxia de forma negativa, ou seja, tudo aquilo que não é a ortodoxia. Ou de forma positiva, como uma categoria intelectual que não é definida exclusivamente em oposição à ortodoxia, o que pode gerar uma combinação vazia visto que entende não haver alguma característica comum a todos os programas de pesquisa ditos heterodoxos.

De acordo com Caldwell (1985) os pluralistas encorajam a teorização econômica em ambas as abordagens heterodoxa e ortodoxa. O ponto do pluralismo é de que através da diversidade de ideias as diferentes posições acerca de um assunto se tornam bem definidas, inteligíveis e compreensíveis. O pluralismo econômico não diz que tudo é aceitável e que não há um padrão para o que é ciência, no entanto também não aceita dizer que só há um jeito de estudar a ciência econômica. O papel chave do pluralismo é o criticismo, que é visto como uma ferramenta para reconhecer forças e fraquezas nos programas de pesquisa.

Até agora não utilizamos o termo "mainstream" visto que este trabalho entende que este serve para indicar a linha de pesquisa que está "na vitrine" da ciência. Ou seja, o mais popular. Como este trabalho se preocupa com o que está sendo ensinado e produzido nos programas de mestrado em economia no brasil, na dualidade ortodoxia/heterodoxia e propondo alguns centros mistos (pluralistas), a discussão do que é ou não mainstream se vê apartada do objetivo da pesquisa. No entanto, abaixo Lee (2010) utiliza o mainstream como o oposto à heterodoxia, o que pode ser criticado facilmente se for levado em conta que trabalhos ditos heterodoxos já foram premiados com o Nobel de economia, como por exemplo o uso de Economia Comportamental (heterodoxa) de Richard Thaler. De qualquer forma, a análise de Lee (2010) consta no trabalho para que se possa entender melhor essas dualidades heterodoxia/ortodoxia.

Para Lee (2010), a economia encontra-se dividida em ao menos dois grupos diferentes, o mainstream e os heterodoxos. O primeiro grupo praticaria o ecumenicalismo, ou como ele chama "pluralismo interno", e trata o outro grupo com intolerância, como um irmão herético.

A escolha da palavra heresia por parte de Lee, já sugere uma pista de como ele enxerga a situação. Ou seja, o mainstream seria uma instituição, quase uma igreja, com suas doutrinas e outras características, e a heterodoxia estaria indo em desacordo com essas doutrinas. 
Lee (2010) coloca que existem avanços na heterodoxia que muitas vezes são tratados como heresias em primeira instancia pelo mainstream, mas que depois se tornam respeitados por este, e então assim ficaria caracterizado um "pluralismo interno". Surge um problema quando um autor ou texto cruza uma fronteira e passa a ser considerado heterodoxo; a partir deste momento, seus colegas do mainstream não mais o respeitarão.

Estabelece ainda que economistas heterodoxos, entre outros conceitos, compõem um corpo dinâmico que desenvolve teorias que derivam em muitas contribuições para diferentes escolas heterodoxas cujos resultados podem render recomendações de políticas públicas. Diz que dentro da heterodoxia, o pluralismo se refere à um engajamento entre diferentes abordagens heterodoxas e a um comprometimento com uma maior integração da comunidade.

Esta argumentação de Lee parece defender o pluralismo como uma ideia virtuosa. Ou seja, quanto mais plural o arcabouço, maiores ganhos para a comunidade científica que podem servir na recomendação de políticas públicas. Bianchi (1992) defende esta ideia de pluralismo virtuoso, quando diz que "Afinal, é um ganho, e não uma perda, o fato de uma comunidade científica complexa ser eclética e comportar diferentes correntes." (p. 141). Essa ideia é completamente contrária à ideia de Colander (2010), de que o pluralismo é uma desculpa dos que não conseguem se adequar ao mainstream, e que não há por que clamar por pluralismo. Analisando desta forma, parece que Colander não compartilha dessa visão de pluralismo virtuoso no panorama da economia atual.

É de se pontuar que a ideia de Bianchi (1992) de que o pluralismo virtuoso pode auxiliar na recomendação de políticas públicas pode ser criticada. Afinal, ter uma gama de estudiosos utilizando diferentes escolas de pensamento e deixando suas opiniões disponíveis para o legislador decidir o que fazer, pode deixá-lo confuso. Este trabalho entende que a divergência de ideias na ciência deve ser encorajada para que o debate científico ocorra e se chegue a um consenso mais robusto, visto que o criticar científico leva a discussão a uma maior qualidade. Assim sendo, o pluralismo virtuoso pode ocorrer no sentido de gerar ciência mais criticada e que abrange mais perspectivas, portanto, mais polidas para que se chegue no legislador um estudo mais robusto, criticado e revisado. Para auxiliar a tomada de políticas públicas, o consenso polido com certeza auxilia mais que a divergência de ideias.

Lee (2010) vai defender essa convergência pluralista na heterodoxia através de suas pesquisas, bem como defenderá que há um movimento anti-pluralista estruturado na comunidade anglo-americana de economistas. Os dados que ele levanta demonstram que 
no Reino Unido, aproximadamente $60 \%$ dos graduandos e $77 \%$ dos graduados não recebem exposição alguma à heterodoxia, e mais de $40 \%$ dos departamentos de Economia não tem sequer um economista heterodoxo contratado (o que inclui quase todos os departamentos mais bem-conceituados). Enfatiza que somente em universidades menores há alguma exposição à heterodoxia que gere trabalhos de conclusão de curso de cunho heterodoxo.

Se ao refletir sobre este assunto se utilizar a premissa de que as pesquisas dos economistas são ferramentas que podem ser empregadas pelos poderes públicos para obterem informações que ajudem na tomada de decisões, e talvez também para a implementação de políticas públicas, parece razoável defender que com o pluralismo exista uma maior quantidade de ideias sendo debatidas, de diferentes pontos de vista e perspectivas. Poder-se-á, assim, contar com o máximo de possibilidades para ser levadas em consideração na hora de tomar uma decisão. No entanto, se houver um caminhar para uma convergência anti-pluralista aproximar-nos-emos de uma redução dessa diversidade de perspectivas sobre o mesmo problema, provocando até um empobrecimento do debate. Esta linha de raciocínio reforça o conceito de pluralismo virtuoso, dadas as ressalvas anteriores.

Para reforçar o argumento de Lee (2010), é possível utilizar a redação de Colander, Holt e Rosser (2004, p. 497), quando ele diz que em 1997, o mainstream aceitou (palavra importante) muitos dos métodos e abordagens associados à economia da complexidade. No entanto não aceitaram a visão da complexidade como um todo. Diz que essa visão é compartilhada apenas por um pequeno grupo de economistas e ela pode ou não ser aceita pelos demais economistas que estão na ponta do campo. Essas afirmações de Colander reforçam a ideia que Lee (2010) está defendendo. Que o mainstream é o detentor do poder, e aceita ou não as ideias heterodoxas quando o convém, sendo então não tão eclético assim como Colander diz.

Colander (2010) inclusive propõe um guia de instruções para que os heterodoxos possam se adequar aos padrões mainstream, para que consigam participar da competição. Ele sugere que os heterodoxos parem de criticar os problemas da profissão, que foquem em áreas onde são especialistas; sugere que a heterodoxia é uma incubadora de ideias, mas que depois de incubadas essas ideias devem ser preparadas para apresentação ao mainstream; que os heterodoxos devem ver a matematizarão como uma aliada; recomenda aos heterodoxos que se associem às organizações do mainstream, que se preocupem 
menos com metodologia, e que não clamem por justiça perante à supremacia do mainstream, dado que este não tem interesse algum em abrir mão de seu poder.

Então, enquanto Colander $(2000,2004,2010)$ está advogando que o mainstream é eclético (e da forma como este trabalho analisa o contexto exposto acima, parece que essa palavra realmente não seja adequada) e não precisa de mais pluralismo, Lee $(2010,2011)$ parece defender o pluralismo virtuoso e mostra um ambiente onde o mainstream está se fechando contra a heterodoxia.

Nas seguintes seções há uma tentativa de aproximação deste debate com o caso Brasileiro. Analisam-se os programas de mestrado em economia no Brasil e categorizamse os programas em ortodoxos, pluralista-ortodoxos, pluralistas, pluralista-heterodoxos ou heterodoxos. Utilizam-se as disciplinas obrigatórias ofertadas para classificar estes programas.

\section{AS DISCIPLINAS OBRIGATÓRIAS DOS PROGRAMAS DE MESTRADO EM ECONOMIA NO BRASIL}

Esta seção analisa as disciplinas obrigatórias dos programas de mestrado em economia no Brasil. Exclui-se da análise o Programa de Pós-Graduação em Desenvolvimento Sustentável do Trópico Úmido da Universidade Federal do Pará, visto que este se trata de um programa que apesar de estar associado ao conselho deliberativo da ANPEC não é um programa exclusivamente de Economia e seria classificado inteiramente como heterodoxo, visto que as disciplinas cadastradas não são as mesmas e não tem comparabilidade. Restam então 56 centros para análise.

\subsection{Metodologia}

Com o intuito de classificar os centros de pesquisa, desenvolveu-se um método para classificar as disciplinas obrigatórias (abaixo) e um método diferente para classificar os centros de pesquisa em si. A classificação dos centros de pesquisa é simples de compreender quando se analisa a tabela presentes no tópico seguinte do trabalho. A tabela lista os centros de pesquisa, as disciplinas obrigatórias, a classificação das disciplinas e a classificação dos centros.

Se o centro de pesquisa tem em sua maioria disciplinas obrigatórias classificadas como ortodoxas, o centro é classificado como ortodoxo. Se a maioria das disciplinas é 
classificada como heterodoxa, o centro recebe a classificação de heterodoxo. Se não há uma maioria explícita, o centro é classificado como pluralista.

Quando há poucas informações disponíveis, ou apenas duas disciplinas obrigatórias classificáveis (micro e macro) é possível que haja uma dificuldade de classificação nos três parâmetros acima. Por este motivo foram criadas mais duas classificações: os centros pluralista-ortodoxos e os centros pluralista-heterodoxos. Esses dizem respeito à centros que tem uma disciplina que foi classificada como pluralista, e a outra disciplina como ortodoxa ou heterodoxa, respectivamente. Em alguns outros casos, com mais disciplinas para análise, o centro também recebe estas classificações mistas, que indicam que o centro é pluralista, mas com alguma tendência metodológica.

Para classificar as disciplinas obrigatórias utilizou-se a ementa da disciplina disponível no website de cada centro e as referências bibliográficas referenciadas, quando disponibilizadas. Quando estas não estavam disponíveis, entrou-se em contato com o programa de pós-graduação por e-mail, e quando não se obteve retorno, utilizou-se a informação disponível na Plataforma Sucupira. Cada disciplina foi categorizada em uma das três classificações tradicionais (ortodoxa, pluralista ou heterodoxa).

A maioria das categorizações dizem respeito às disciplinas de Macroeconomia e Microeconomia. Por este motivo, detalhar-se-ão nas páginas seguintes quais componentes curriculares que, quando identificados em uma ementa de disciplina, indicam se a disciplina é heterodoxa, ou ortodoxa. E quando esta disciplina contempla uma mescla desses componentes curriculares, classifica-se a disciplina como pluralista.

Como não é possível listar todos os itens que aparecem nas ementas dos cursos analisados, dada a grande quantidade de informação, lista-se abaixo uma amostra dos conteúdos encontrados nas ementas que sugerem tendência, separados por tipo de classificação. Com certeza alguns clássicos deixarão de aparecer na relação abaixo, visto que só constam as informações encontradas nas ementas disponibilizadas pelos programas de mestrado.

Ainda para afinar o critério, foram selecionados alguns programas para servirem de modelo. Os programas escolhidos para representar o currículo ortodoxo foram IPE/USP, EPGE/FGV-RJ, PPGEA/UFV, PPEA/UFOP e PPGE/FURG. Os programas escolhidos para representar o currículo heterodoxo foram PUC/SP, IE/UNICAMP, PPGE/UFU e PPGE/UFABC disciplinas "B". As disciplinas de macroeconomia e microeconomia do PPGE/UFABC também foram utilizadas como referência visto que estas são divididas em $A$ e $B$, para ortodoxo e heterodoxo respectivamente. 


\subsubsection{Microeconomia}

Disciplinas que contemplam conteúdos como os descritos abaixo, ou as bibliografias citadas abaixo, indicam que a disciplina de microeconomia deste centro tenderá a ser classificada como ortodoxa:

- Teoria do Equilíbrio Geral;

- Incerteza e risco: modelo baseado na utilidade esperada;

- Teoria clássica da demanda;

- Teoremas da maximização dos lucros e da produção e minimização dos custos;

- Equilíbrio Walrasiano;

Bibliografias que indicam que a classificação tenderá a ser ortodoxa:

- MAS-COLELL, A.; WHINSTON, M.D; GREEN, J.R. Microeconomic theory. New York, USA: Oxford University Press, c1995. (Aparece em 100\% dos programas escolhidos como representantes de currículo ortodoxo.)

- VARIAN, H.R. Microeconomic analysis. 3. ed. New York, USA: W. W. Norton \& Company, c1992. (Aparece em 80\% dos programas representantes)

- JEHLE, G. A.; RENY, P. J. (2011). Advanced Microeconomic Theory. $3^{\mathrm{a}}$ Edition. Harlow, Essex: Financial Times Prentice Hall - Pearson. (Aparece em $100 \%$ dos programas escolhidos como representantes de currículo ortodoxo.)

Disciplinas que contemplam conteúdos como os descritos abaixo, ou as bibliografias citadas abaixo, indicam que a disciplina de microeconomia deste centro tenderá a ser classificada como heterodoxa:

- Redação explicita "correntes teóricas alternativas à ortodoxia";

- Teoria da Racionalidade Limitada;

- Economia Institucional;

- Economia Comportamental;

- Economia Feminista;

- Abordagem Evolucionista;

Bibliografias que indicam que a classificação tenderá a ser heterodoxa: 
- HODGSON, Geoffrey M. Institutional Economics into the Twenty-First Century. Studi e Note di Economia, 2009.

- HODGSON, Geoffrey M. Conceptualizing Capitalism: Institutions, Evolution, Future. Chicago: University of Chicago Press, 2015. (Trabalhos do Hodgson aparecem em $50 \%$ dos programas representantes)

- BOWLES, S. Microeconomics: behavior, institutions and evolution. New York: Russell Sage Foundation, 2004. (Em 50\% dos programas representantes)

\subsubsection{Macroeconomia}

Disciplinas que contemplam conteúdos como os descritos abaixo, ou as bibliografias citadas abaixo, indicam que a disciplina de macroeconomia deste centro tenderá a ser classificada como ortodoxa:

- Modelo de Solow;

- Modelo de Ramsey;

- Modelo de Ramsey-Cass-Koopmans em tempo contínuo e discreto;

- Modelo de Gerações Sobrepostas;

- Teoria dos ciclos reais de negócios;

- Modelos de crescimento estocásticos;

Bibliografias que indicam que a classificação tenderá a ser ortodoxa:

- BARRO, R. J.; SALA-I-MARTIN, X. Economic Growth. 2nd. Edition. Cambridge: The MIT Press, 2003. (Trabalhos de Barro aparecem em 50\% dos programas representantes)

- BLANCHARD, O.; FISCHER, S. Lectures on Macroeconomics. Cambridge, MA: MIT Press, 1989. (Presente em $65 \%$ dos programas representantes)

- ROMER, D. Advanced macroeconomics. 4rd Boston: McGraw-Hill Irwin, 2012. (Presente em 100\% dos programas representantes)

Disciplinas que contemplam conteúdos como os descritos abaixo, ou as bibliografias citadas abaixo, indicam que a disciplina de macroeconomia deste centro tenderá a ser classificada como heterodoxa: 
- Redação explicita "correntes teóricas alternativas à ortodoxia".

- Teoria Keynesiana;

- Teoria Pós-Keynesiana;

- Princípio da Demanda Efetiva;

- O papel dos "animal spirits" e da incerteza fundamental;

- A teoria da não neutralidade da moeda;

- Teoria Marxista;

\section{Bibliografias que indicam que a classificação tenderá a ser heterodoxa:}

- Kalecki, M. Teoria da Dinâmica Econômica. $2^{\circ}$. Edição, São Paulo, Nova Cultural, 1985; (Presente em 50\% dos programas representantes)

- Keynes, J.M. A Teoria Geral do Emprego, do Juro e da Moeda. $2^{\circ}$. Edição, São Paulo, Nova Cultural, 1985; (Presente em 100\% dos programas representantes)

- LAVOIE, M. Introduction to Post-Keynesian Economics. Palgrave/Macmillan, 2006; (Presente em $75 \%$ dos programas representantes)

\subsection{Dados}

Como o objetivo é classificar cada disciplina, com exceção das disciplinas obrigatórias relacionadas à econometria e/ou matemática como dito anteriormente, a análise utilizou como bússola para classificações componentes similares aos que constam no tópico anterior (2.1).

Após a análise das disciplinas de cada centro de pesquisa, o curso de mestrado foi catalogado a partir da maior prevalência de classificação das disciplinas, com exceção de 7casos sem uma maioria explicita que foram classificados como Pluralista-Ortodoxo, 1 como Pluralista-Heterodoxo e 2 casos que tiveram classificação pluralista pois suas disciplinas obrigatórias foram classificadas de forma equilibrada, ou seja, a mesma quantidade de disciplinas obrigatórias classificadas como ortodoxas e heterodoxas.

A relação completa das classificações dos 56 programas analisados consta na tabela 1 a seguir. Analisando estes programas é possível identificar que 27 foram classificados como ortodoxos (48\%), 7 como pluralista-ortodoxos (12\%), 15 como pluralistas (27\%), 1 como pluralista-heterodoxo (2\%) e 6 como heterodoxos (11\%). 
Somando os programas classificados como pluralistas e pluralistaortodoxo/heterodoxo há um total de $41 \%$ de programas que abordam ambas as perspectivas em suas disciplinas obrigatórias.

As classificações das disciplinas na tabela foram realizadas em siglas. Classificação $\mathrm{H}$ significa heterodoxo, O para ortodoxo, $\mathrm{P}$ para pluralista, $\mathrm{PO}$ para pluralista-ortodoxo e $\mathrm{PH}$ para pluralista-heterodoxo. As disciplinas quantitativas também foram classificadas em siglas: MAT corresponde à Economia Matemática, ECO para Econometria, QUA para Métodos Quantitativos em Economia e NIV para Nivelamento Matemático.

Seria possível admitir uma supremacia ortodoxa neste grupo? Com uma comparação simplista ortodoxos (27) versus heterodoxos (6) é possível dizer que sim. No entanto ao incluir na análise as 23 variações pluralistas é possível ver que há um esforço em explorar as diferentes vertentes metodológicas nas disciplinas obrigatórias dos programas listados. Ainda que haja uma maioria de cursos com inclinação ortodoxa (34) se comparado com os demais programas (22). Uma hipótese que poderia explicar essa maioria é a de que ela vem de uma ideia de que o básico da economia é a ortodoxia, e que nas disciplinas obrigatórias haja uma necessidade de revisitar este básico para todos os alunos. 
Tabela 1: Programas de mestrado em economia classificados por disciplina.

\begin{tabular}{|c|c|c|c|c|c|}
\hline Programa & $\begin{array}{c}\text { Micro } \\
1\end{array}$ & $\begin{array}{c}\text { Macro } \\
1\end{array}$ & Quantitativa & $\begin{array}{l}\text { Outras Disciplinas } \\
\text { Obrigatórias }\end{array}$ & Classificação \\
\hline CAEN/UFC & o & o & ECO, MAT & $\begin{array}{c}\text { Micro } 2(\mathrm{O}) \text { Macro } 2 \\
(\mathrm{O})\end{array}$ & Ortodoxo \\
\hline CEDEPLAR/UFMG & 0 & 0 & MAT, ECO & - & Ortodoxo \\
\hline EESP/FGV-SP & 0 & 0 & $\begin{array}{l}\text { ECO 1\&2, MAT, } \\
\text { ESTA }\end{array}$ & $\begin{array}{c}\text { Macro } 2(\mathrm{O}), \text { Macro } \\
\text { Brasileira (P), Micro } 2 \\
\text { \& } 3(\mathrm{O}) \\
\end{array}$ & Ortodoxo \\
\hline EPGE/FGV-RJ & $\mathrm{O}$ & $\mathrm{O}$ & MAT & $\begin{array}{l}\text { Micro } 2 \& 3(\mathrm{O}) \text {, Macro } \\
2 \& 3(\mathrm{O})\end{array}$ & Ortodoxo \\
\hline IE/UFRJ & $P$ & $P$ & QUA & - & Pluralista \\
\hline $\begin{array}{l}\text { IE/UNICAMP (Ciência } \\
\text { Econômica) }\end{array}$ & $\mathrm{H}$ & $\mathrm{H}$ & ECO & $\begin{array}{c}\text { Economia Brasileira } \\
(\mathrm{H}), \text { Economia Política } \\
(\mathrm{H})\end{array}$ & Heterodoxo \\
\hline $\begin{array}{l}\text { IE/UNICAMP (Economia do } \\
\text { Desenvolvimento) }\end{array}$ & $\mathrm{H}$ & $\mathrm{H}$ & QUA & $\begin{array}{c}\text { Desenvolvimento } \\
\text { Econômico }(\mathrm{H}), \\
\text { Economia Brasileira e } \\
\text { Internacional }(\mathrm{H})\end{array}$ & Heterodoxo \\
\hline INSPER & 0 & 0 & $\begin{array}{l}\text { MAT, ECO, } \\
\text { ESTA }\end{array}$ & $\begin{array}{l}\text { Métodos Analíticos }(\mathrm{x}), \\
\text { Finanças } 1 \& 2(\mathrm{O})\end{array}$ & Ortodoxo \\
\hline IPE/USP & $\mathrm{O}$ & 0 & ECO, MAT & $\begin{array}{c}\text { Micro } 2(\mathrm{O}), \text { Macro } 2 \\
(\mathrm{O})\end{array}$ & Ortodoxo \\
\hline Mackenzie - Profissional & 0 & 0 & MAT, ECO & - & Ortodoxo \\
\hline ME/UFAL & $\mathrm{P}$ & $\mathrm{H}$ & QUA, ECO & $\begin{array}{c}\text { Economia da Inovação } \\
(\mathrm{H}), \text { Economia do } \\
\text { Desenvolvimento }(\mathrm{P})\end{array}$ & $\begin{array}{l}\text { Pluralista- } \\
\text { Heterodoxo }\end{array}$ \\
\hline ME/UFV & 0 & 0 & MAT & - & Ortodoxo \\
\hline NUPEC/UFS & $\mathrm{O}$ & $\mathrm{H}$ & MAT, ECO & $\begin{array}{c}\text { Teorias do } \\
\text { Desenvolvimento }(\mathrm{H}), \\
\text { Economia Política } 1(\mathrm{H})\end{array}$ & Heterodoxo \\
\hline PCE/UEM & $\mathrm{P}$ & $\mathrm{P}$ & QUA, ECO & - & Pluralista \\
\hline PIMES/UFPE & 0 & 0 & $\begin{array}{l}\text { MAT, ECO, } \\
\text { ESTA }\end{array}$ & - & Ortodoxo \\
\hline PPE/UEL & 0 & $\mathrm{P}$ & $\begin{array}{l}\text { MAT, ESTA, } \\
\text { ECO }\end{array}$ & $\begin{array}{c}\text { Economia Regional I } \\
(\mathrm{P})\end{array}$ & Pluralista \\
\hline PPE/UERN & 0 & 0 & $\begin{array}{l}\text { MAT, ECO, } \\
\text { ESTA }\end{array}$ & Metodologia (x) & Ortodoxo \\
\hline PPE/UFG & 0 & 0 & ECO, MAT & - & Ortodoxo \\
\hline PPEA/UFOP & 0 & 0 & $\begin{array}{l}\text { MAT, ECO, } \\
\text { ESTA }\end{array}$ & - & Ortodoxo \\
\hline PPECO/UFRN & $\mathrm{O}$ & $\mathrm{O}$ & ECO & - & Ortodoxo \\
\hline PPED/UNIFESP & $\mathrm{P}$ & $\mathrm{P}$ & ECO & $\begin{array}{c}\text { Economia Brasileira } \\
(\mathrm{H})\end{array}$ & Pluralista \\
\hline PPGCE/UERJ & 0 & 0 & QUA, ECO & $\begin{array}{c}\text { Micro } 2 \text { (O), Macro } 2 \\
(\mathrm{O})\end{array}$ & Ortodoxo \\
\hline PPGDE/UFPR & 0 & 0 & MAT, ECO & - & Ortodoxo \\
\hline PPGDSE/UFMA & 0 & $\mathrm{P}$ & QUA & $\begin{array}{c}\text { Teorias do } \\
\text { Desenvolvimento } \\
\text { Socioeconômico }(\mathrm{H}), \\
\text { Metodologia }(\mathrm{x}) \\
\text { Economia Política }(\mathrm{H}) \\
\end{array}$ & Heterodoxo \\
\hline PPGE\&D/UFSM & $P$ & $\mathrm{H}$ & ECO & $\begin{array}{c}\text { Teorias do } \\
\text { Desenvolvimento }(\mathrm{P})\end{array}$ & Pluralista \\
\hline PPGE/Mar-FURG & 0 & 0 & QUA, ECO & Microeconometria $(\mathrm{O})$ & Ortodoxo \\
\hline PPGE/PUC-RS & $P$ & $\mathrm{P}$ & MAT, ECO & $\begin{array}{l}\text { Desenvolvimento } \\
\text { Econômico }(\mathrm{P})\end{array}$ & Pluralista \\
\hline
\end{tabular}




\begin{tabular}{|c|c|c|c|c|c|}
\hline PPGE/UFABC & $\mathrm{P}$ & $\mathrm{P}$ & ECO & $\begin{array}{c}\text { Pluralismo na } \\
\text { Economia }(P), \\
\text { Seminários de Tese }(x)\end{array}$ & Pluralista \\
\hline PPGE/UFBA & $\mathrm{O}$ & $P$ & MAT, ECO & Economia Política $1(\mathrm{H})$ & Pluralista \\
\hline PPGE/UFF & $\mathrm{P}$ & $\mathrm{P}$ & MAT & $\begin{array}{c}\text { História do } \\
\text { Pensamento } \\
\text { Econômico }(\mathrm{P})\end{array}$ & Pluralista \\
\hline PPGE/UFJF & 0 & 0 & $\begin{array}{l}\text { MAT, QUA } 1 \& 2, \\
\text { ESTA }\end{array}$ & & Ortodoxo \\
\hline PPGE/UFMT & 0 & $\mathrm{P}$ & QUA, ECO & $\begin{array}{c}\text { Economia do } \\
\text { Agronegócio }(\mathrm{P}) \text {, } \\
\text { Teoria do } \\
\text { Desenvolvimento }(\mathrm{P})\end{array}$ & Pluralista \\
\hline PPGE/UFPA & $\mathrm{P}$ & $\mathrm{P}$ & ECO, QUA & $\begin{array}{l}\text { Economia Política }(\mathrm{H}), \\
\text { Macro } 2(\mathrm{P}), \text { Micro } 2 \\
\text { (P) }\end{array}$ & Pluralista \\
\hline $\begin{array}{l}\text { PPGE/UFRGS - Economia } \\
\text { Aplicada }\end{array}$ & $\mathrm{O}$ & $\mathrm{O}$ & MAT, ECO & 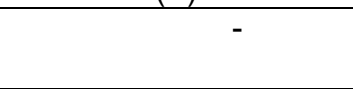 & Ortodoxo \\
\hline $\begin{array}{l}\text { PPGE/UFRGS - Economia } \\
\text { do Desenvolvimento }\end{array}$ & $\mathrm{P}$ & $\mathrm{H}$ & ECO & $\begin{array}{c}\text { Teorias do } \\
\text { Desenvolvimento }(P)\end{array}$ & Pluralista \\
\hline PPGE/UFU & $\mathrm{P}$ & $\mathrm{H}$ & QUA & $\begin{array}{c}\text { Políticas Públicas }(\mathrm{H}) \text {, } \\
\text { Problemas do } \\
\text { Desenvolvimento } \\
\text { Brasileiro }(\mathrm{H})\end{array}$ & Heterodoxo \\
\hline PPGE/UNILA & O & $\mathrm{P}$ & $\begin{array}{l}\text { QUA, ESTA, } \\
\text { ECO }\end{array}$ & - & $\begin{array}{l}\text { Pluralista- } \\
\text { Ortodoxo }\end{array}$ \\
\hline PPGE/Unisinos & $\mathrm{O}$ & $\mathrm{P}$ & QUA & - & $\begin{array}{l}\text { Pluralista- } \\
\text { Ortodoxo }\end{array}$ \\
\hline PPGE/USP-RP & 0 & 0 & $\begin{array}{l}\text { MAT, ECO, } \\
\text { ESTA }\end{array}$ & Metodologia (x) & Ortodoxo \\
\hline PPGEA/UFV & $\mathrm{O}$ & 0 & ECO, MAT & - & Ortodoxo \\
\hline PPGEA/USP-ESALQ & 0 & 0 & $\begin{array}{l}\text { MAT, ECO, } \\
\text { ESTA }\end{array}$ & $\begin{array}{c}\text { Economia } \\
\text { Contemporânea }(\mathrm{P})\end{array}$ & Ortodoxo \\
\hline PPGEC/UFSCAR & $\mathrm{O}$ & $\mathrm{O}$ & MAT, ECO & Metodologia $(x)$ & Ortodoxo \\
\hline PPGEco/UEPG & $\mathrm{O}$ & $\mathrm{O}$ & QUA, ECO & - & Ortodoxo \\
\hline PPGEco/UFES & $\mathrm{P}$ & $P$ & ECO & - & Pluralista \\
\hline PPGEco/UFSC & $\mathrm{O}$ & $\mathrm{P}$ & QUA, ECO & - & $\begin{array}{l}\text { Pluralista- } \\
\text { Ortodoxo }\end{array}$ \\
\hline PPGECON/UFPE & $\mathrm{O}$ & $\mathrm{O}$ & ESTA, MAT & $\begin{array}{c}\text { Economia Regional } \\
(P), \text { Economia Agrícola } \\
(P)\end{array}$ & $\begin{array}{l}\text { Pluralista- } \\
\text { Ortodoxo }\end{array}$ \\
\hline PPGEconomia/UNIFAL-MG & 0 & $\mathrm{P}$ & ECO & $\begin{array}{c}\text { Economia Brasileira } \\
(\mathrm{H})\end{array}$ & Pluralista \\
\hline PPGE-JP/UFPB & 0 & O & MAT, ESTA & $\begin{array}{c}\text { Micro } 2 \text { (O), Macro } 2 \\
(\mathrm{P})\end{array}$ & Ortodoxo \\
\hline PPGER/UFRRJ & $\mathrm{O}$ & $\mathrm{P}$ & QUA & $\begin{array}{c}\text { Economia do } \\
\text { Desenvolvimento }(\mathrm{P}), \\
\text { Economia Regional }(\mathrm{P})\end{array}$ & Pluralista \\
\hline PPGOM/UFPel & $\mathrm{O}$ & O & $\begin{array}{l}\text { MAT 1\&2, } \\
\text { ESTA, ECO }\end{array}$ & & Ortodoxo \\
\hline PUC-RJ & $\mathrm{O}$ & $\mathrm{P}$ & $\begin{array}{l}\text { MAT, ESTA, } \\
\text { ECO }\end{array}$ & Micro $2(\mathrm{O})$ & Ortodoxo \\
\hline PUC-SP & $\mathrm{H}$ & $\mathrm{H}$ & MAT & $\begin{array}{c}\text { Economia Brasileira I } \\
(\mathrm{H}), \text { Economia Política } \\
(\mathrm{H})\end{array}$ & Heterodoxo \\
\hline UCB & $\mathrm{O}$ & 0 & MAT, ECO & Epistemologia $(\mathrm{x})$ & Ortodoxo \\
\hline UnB & 0 & $\mathrm{P}$ & MAT, ECO & - & $\begin{array}{l}\text { Pluralista- } \\
\text { Ortodoxo }\end{array}$ \\
\hline UNESP & 0 & $\mathrm{P}$ & MAT, ECO & - & $\begin{array}{l}\text { Pluralista- } \\
\text { Ortodoxo }\end{array}$ \\
\hline UNIOESTE & 0 & $\mathrm{P}$ & $\begin{array}{c}\text { MAT, ECO, } \\
\text { ESTA }\end{array}$ & - & $\begin{array}{l}\text { Pluralista- } \\
\text { Ortodoxo }\end{array}$ \\
\hline
\end{tabular}


FONTE: ELABORAÇÃO PRÓPRIA.

É interessante destacar que algumas universidades sinalizam em seu website sua característica plural, como é o caso da UFRGS e da UFRJ ilustrados a seguir. Esses programas foram classificados como pluralistas na tabela apresentada anteriormente.

Figura 1: Logotipo da UFRGS 85 anos

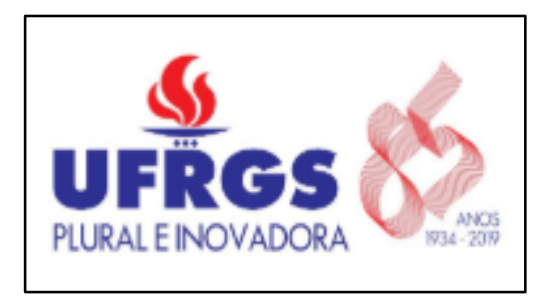

FONTE: WEBSITE DA UFRGS

Figura 2: Captura de tela do Website do IE/UFRJ

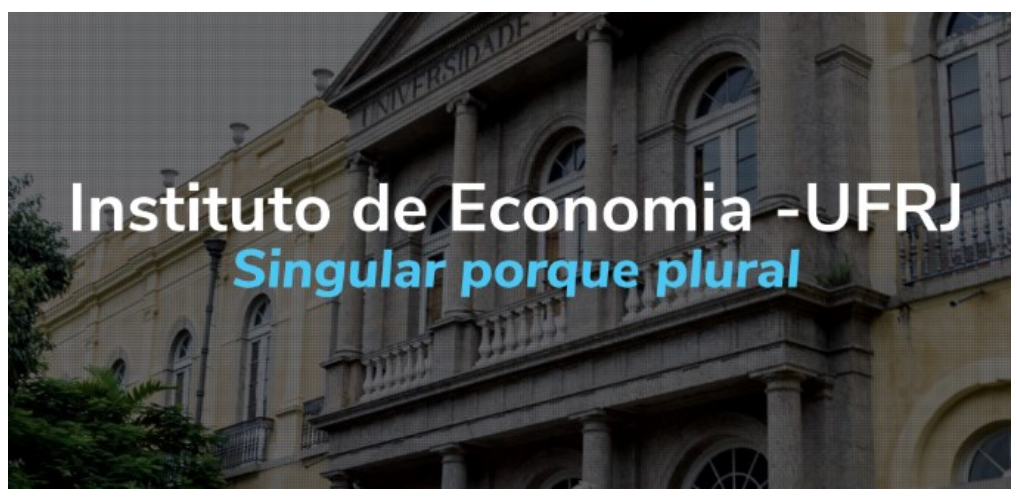

FONTE: WEBSITE DO IE/UFRJ

Seriam então os programas de mestrado em economia no Brasil pluralistas? Não, ao menos no que diz respeito às suas disciplinas obrigatórias. Mas $41 \%$ destes programas são pluralistas, o que já é um valor relativamente bom se o ensino pluralista for visto como algo a ser buscado.

Na próxima seção é feita uma análise agregada dos centros de todo o país e suas classificações.

\subsection{Considerações Finais}

Este estudo consistiu em uma tentativa de classificação dos programas de mestrado em economia no Brasil através da análise das ementas e referências bibliográficas de cada 
uma das disciplinas obrigatórias de cada programa. A metodologia de classificação foi exposta na seção 2.1 e na seção 2.2 os dados foram expostos com detalhe.

Olhando de perto os 56 programas analisados tem-se que a classificação geral obtida é de 27 programas ortodoxos (48\%), 7 programas pluralista-ortodoxos (12\%), 15 programas pluralistas (27\%), 1 programa pluralista-heterodoxo (2\%) e 6 programas heterodoxos (11\%).

Analisando mais a fundo entende-se que, utilizando esta metodologia, quase metade dos programas de mestrado em economia no Brasil realizam esforços para abordar aspectos tanto ortodoxos quanto heterodoxos, recebendo então uma classificação pluralista, ainda que com suas inclinações (41\%).

Percebe-se também que a ortodoxia continua com o maior espaço nas disciplinas obrigatórias. Como comentado anteriormente, pode ser que isso ocorra devido à um pensamento de que nas disciplinas obrigatórias o que é ensinado deve ser o tradicional da economia (ortodoxo). Mas para testar essa hipótese seria necessário analisar as disciplinas optativas ofertadas pelos centros, o que não é o objetivo deste trabalho.

Este tipo de análise é interessante pois mostra que há uma preocupação dos programas em mostrar as diferenças das correntes de pensamento na economia, mesmo nas disciplinas obrigatórias dos cursos. Inclusive, como consta no tópico anterior, em alguns websites dos programas existem frases denotando que há um esforço em busca do pluralismo por parte do centro.

Este trabalho entende que classificar os programas apenas por esta ótica corresponde uma classificação simplista, por isso deixa recomendações para outros trabalhos, para que façam classificações utilizando mais metodologias como o levantamento da classificação do corpo docente; das classificação das disciplinas optativas ofertadas; da classificação das dissertações produzidas; da classificação dos assuntos levados aos seminários regulares (que ocorrem em muitos dos centros) e a percepção dos alunos quanto à classificação do programa, das disciplinas ofertadas, do corpo docente e discente, das dissertações produzidas e dos seminários.

FERNANDEZ e SUPRINYAK (2019) fizeram um levantamento parecido, onde classificaram os discentes nas categorias ortodoxo, heterodoxo ou pluralista ao interpretar seus currículos e então classificaram cada programa nestas mesmas categorias. Utilizaram também outras fontes de informação para ajudar na classificação dos centros, como as disciplinas obrigatórias (assim como neste trabalho), dissertações e teses produzidas, tópicos e métodos de pesquisa, entre outras. O resultado que colheram equivale a $28 \%$ dos 
programas ortodoxos, $41 \%$ pluralistas, e $31 \%$ heterodoxos. Para efeito de comparação com o resultado deste trabalho, remove-se aqui as classificações pluralista-ortodoxo e pluralistaheterodoxo, obtendo-se então $48 \%$ ortodoxos, $41 \%$ pluralistas e $1 \%$ heterodoxo. Nota-se diferença no que diz respeito à classificação dos cursos ao comparar os dois estudos. Pode ser que estas diferenças tenham influência forte do fato de não constarem os programas de doutorado na pesquisa deste trabalho, no entanto é possível que as diferenças se reduzam ao incluir na análise as dissertações produzidas ou os demais fatores sugeridos.

\section{REFERÊNCIAS}

ASSOCIAÇÃO NACIONAL DOS CENTROS DE PÓS-GRADUAÇÃO EM ECONOMIA. Centros Associados. Niterói, 2021. Disponível em: <http://www.anpec.org.br/novosite/br/centros-associados>. Acesso em: 14 mar. 2021.

BIANCHI, A. M. Muitos métodos é o método: A respeito do pluralismo em economia. Revista de Economia Política, vol. 12, n² 2, p. 135-142. 1992.

CALDWELL, B. J. The case for pluralism. IN: DE MARCHI, N. (Org.) (1988). The Popperian legacy in economics: Papers presented at a Symposium in Amsterdam, December 1985. Cambridge, Cambridge University Press, p.231-244. 1985.

CAPES. Sobre a avaliação. Brasília, 2019. Disponível em: <https://uab.capes.gov.br/avaliacao/sobre-a-avaliacao>. Acesso em: 12 de dezembro de 2020 .

COLANDER, D. The Death of Neoclassical Economics. Journal of the History of Economic Thought, [S.L], v. 22, n.2, p. 127-143, jun. 2000.

COLANDER, D.; HOLT, R.; ROSSER, B. The changing face of mainstream economics. Review of Political Economy, [S.L.], v. 16, n. 4, p. 485-499, out. 2004.

COLANDER, D. Moving beyond the rhetoric of pluralism: suggestions for an "inside-themainstream" heterodoxy. How Economics Should Be Done, [S.L], p. 228-239, 2010.

DAVIS, J. B. The turn in economics and the turn in economic methodology. Journal of Economic Methodology, [S.L.], v. 14, n. 3, p. 275-290, set. 2007. 
DEQUECH, D. Neoclassical, mainstream, orthodox, and heterodox economics. Journal of Post Keynesian Economics, [S.L.], v. 30, n. 2, p. 279-302, 1 dez. 2007.

DEQUECH, D. Applying the Concept of Mainstream Economics outside the United States: general remarks and the case of brazil as an example of the institutionalization of pluralism. Journal of Economic Issues, [S.L.], v. 52, n. 4, p. 904-924, 2 out. 2018.

FERNANDEZ, R. G.; SUPRINYAK C. E. Manufacturing Pluralism in Brazilian Economics. Journal of Economic Issues, [S.L.], v. 53, n. 3, p. 748-773, 3 jul. 2019.

LEE, F. Pluralism in heterodox economics. In: GARNETT, E. et al. Economic Pluralism, [S.L.], Routledge Frontier of Political Economy, 2010. P. 19-35.

LEE, F. The pluralism debate in heterodox economics. Review of Radical Political Economics, [S.L.], v. 43, n. 4, p. 540-551, 6 abr. 2011.

PLATAFORMA SUCUPIRA. Disciplinas. Ministério da Educação, 2019. Disponível em:<https://sucupira.capes.gov.br/sucupira/public/consultas/coleta/disciplina/listaDisciplin a.jsf;jsessionid=PuFowGAxcHwmbao158FgvhjJ.sucupira-204>. Acesso em: 11 de setembro de 2019.

PNUD. Desenvolvimento humano nas macrorregiões brasileiras. Brasil, 2016.

Disponível em: <

https://www.ipea.gov.br/portal/images/stories/PDFs/livros/livros/20160331_livro-idhm.pdf>. Acesso em: 20 de dezembro de 2020.

\section{ANEXO A - INSTITUIÇÕES ANALISADAS}

UNIVERSIDADE FEDERAL DO CEARÁ. Programa de Pós-Graduação em Economia. Fortaleza, 2019. Disponível em: <https://caen.ufc.br/>. Acesso em: 16 de setembro de 2019.

UNIVERSIDADE FEDERAL DE UBERLÂNDIA. Programa de Pós-graduação em Economia. Uberlândia, 2019. Disponível em: <http://www.ppge.ie.ufu.br/>. Acesso em: 17 de setembro de 2019.

ECONOMIA. Pontifícia Universidade Católica. São Paulo, 2019. Disponível em: <https://www.pucsp.br/pos-graduacao/mestrado-e-doutorado/economia>. Acesso em: 12 de setembro de 2019.

FUNDAÇÃO GETÚLIO VARGAS. Catálogo de disciplinas. São Paulo, 2019. Disponível em: <https://eesp.fgv.br/sites/eesp.fgv.br/files/catalogo_de_disciplinas.pdf>. Acesso em: 12 de setembro de 2019. 
FUNDAÇÃO GETÚLIO VARGAS. Grade e corpo docente. Rio de Janeiro, 2019. Disponível em: <http://epge.fgv.br/pt/pos-graduacao/doutorado-mestrado/grade>. Acesso em: 12 de setembro de 2019.

UNIVERSIDADE DE SÃO PAULO. Departamento de Economia. São Paulo, 2019. Disponível em: <http://www.fea.usp.br/economia>. Acesso em: 17 de setembro de 2019.

UNIVERSIDADE FEDERAL DE JUIZ DE FORA. Programa de Pós-Graduação em Economia. Juiz de Fora, 2019. Disponível em: <http://www.ufff.br/poseconomia/>. Acesso em: 16 de setembro de 2019.

UNIVERSIDADE DE SÃO PAULO. Faculdade de Economia, Administração e Contabilidade de Ribeirão Preto. Ribeirão Preto, 2019. Disponível em: <https://www.fearp.usp.br/>. Acesso em: 17 de setembro de 2019.

UNIVERSIDADE FEDERAL DE VIÇOSA. Pós-Graduação Stricto Sensu em Economia. Viçosa, 2019. Disponível em: <http://www.poseconomia.ufv.br/>. Acesso em: 17 de setembro de 2019.

UNIVERSIDADE FEDERAL DE SANTA CATARINA. Programa de pós-graduação em economia. Florianópolis, 2019. Disponível em: <http://ppgeco.ufsc.br/oprograma/mestrado/>. Acesso em: 16 de setembro de 2019.

UNIVERSIDADE FEDERAL DE PERNAMBUCO. Programa de Pós-Graduação em Economia. Recife, 2019. Disponível em: <https://www.ufpe.br/ppgecon/>. Acesso em: 16 de setembro de 2019.

UNIVERSIDADE DE SÃO PAULO. Departamento de Economia, Administração e Sociologia. Piracicaba, 2019. Disponível em: <http://www.economia.esalq.usp.br/>. Acesso em: 17 de setembro de 2019.

MAR-FURG. Programa de Pós-graduação em Economia Aplicada. Rio Grande, 2019. Disponível em: <https://ppgeconomia.furg.br/>. Acesso em: 12 de setembro de 2019.

UNIVERSIDADE FEDERAL DA PARAÍBA. Programa de Pós-Graduação em Economia. João Pessoa, 2019. Disponível em: <http://www.ccsa.ufpb.br/ppge/>. Acesso em: $16 \mathrm{de}$ setembro de 2019.

UNIVERSIDADE ESTADUAL DE MARINGÁ. Programa de Pós-Graduação em Ciências Econômicas. Maringá, 2019. Disponível em: <http://www.pce.uem.br/>. Acesso em: 12 de setembro de 2019.

UNIVERSIDADE FEDERAL DA BAHIA. Programa de Pós-Graduação em Economia. Salvador, 2019. Disponível em: <https://ppgeconomia.ufba.br/>. Acesso em: 16 de setembro de 2019.

INSPER. Pós-graduação. São Paulo, 2019. Disponível em:

<https://www.insper.edu.br/pos-graduacao/>. Acesso em: 12 de setembro de 2019. 
MACKENZIE. Economia e Mercados - Profissional. São Paulo, 2021. Disponível em: $<$ https://www.mackenzie.br/pos-graduacao/mestrado-doutorado/sao-paulohigienopolis/economia-e-mercados-profissional/>. Acesso em: 18 de março de 2021.

ECONOMIA do Desenvolvimento. Pontifícia Universidade Católica. Porto Alegre, 2019. Disponível em: <http://www.pucrs.br/negocios/curso/mestrado-em-economia-dodesenvolvimento/>. Acesso em: 12 de setembro de 2019.

UNIVERSIDADE FEDERAL DE OURO PRETO. Programa de Pós-graduação em Economia Aplicada. Mariana, 2019. Disponível em: <http://www.ppea.ufop.br/>. Acesso em: 16 de setembro de 2019.

UNIVERSIDADE FEDERAL DO RIO DE JANEIRO. Instituto de Economia. Rio de Janeiro, 2019. Disponível em: <http://www.ie.ufrj.br/>. Acesso em: 16 de setembro de 2019.

UNIVERSIDADE FEDERAL FLUMINENSE. Programa de Pós-Graduação em Economia. Niterói, 2019. Disponível em: <http://www.ppge.uff.br/>. Acesso em: 16 de setembro de 2019.

UNIVERSIDADE FEDERAL DE SÃO PAULO. Mestrado Acadêmico em Economia e Desenvolvimento. Osasco, 2019. Disponível em:

<https://www.unifesp.br/campus/osa2/destaques-eppen/282-mestrado-academico-emeconomia-e-desenvolvimento>. Acesso em: 17 de setembro de 2019.

UNIVERSIDADE ESTADUAL DE LONDRINA. Mestrado em Economia Regional. Londrina, 2019. Disponível em: <http://www.uel.br/pos/economia/portal/>. Acesso em: 12 de setembro de 2019.

UNIVERSIDADE FEDERAL DO ABC. Disciplinas. Santo André, 2019. Disponível em: $<$ https://sites.google.com/view/ppgeconomiaufabc/acad\%C3\%AAmico/disciplinas?authuse $\mathrm{r}=0$ > . Acesso em: 12 de setembro de 2019.

UNIVERSIDADE FEDERAL DO ESPÍRITO SANTO. Mestrado em Economia. Vitória, 2019. Disponível em: <http://www.economia.ufes.br>. Acesso em: 16 de setembro de 2019.

UNIVERSIDADE CATÓLICA DE BRASÍLIA. Pós-Graduação Católica. Brasília, 2019. Disponível em: <https://inscricaoucb.catolica.edu.br/pos>. Acesso em: 12 de setembro de 2019.

UNIVERSIDADE DE BRASÍLIA. Departamento de Economia. Brasília, 2019. Disponível em: <http://www.economia.unb.br/mestrado-academico>. Acesso em: 17 de setembro de 2019 .

UNIVERSIDADE FEDERAL DE ALFENAS. Programa de Pós-Graduação em Economia. Varginha, 2019. Disponível em: <https://www.unifalmg.edu.br/ppgeconomia/>. Acesso em: 17 de setembro de 2019. 
UNIVERSIDADE ESTADUAL DE SÃO PAULO. Programa de Pós-Graduação em Economia. Araraquara, 2019. Disponível em: <https://www.fclar.unesp.br/\#!/poseconomia>. Acesso em: 17 de setembro de 2019.

UNIVERSIDADE FEDERAL DE ALAGOAS. Mestrado em Economia Aplicada. Maceió, 2019. Disponível em: <http://www.ufal.edu.br/unidadeacademica/feac/posgraduacao/mestrado-em-economia-aplicada-1>. Acesso em: 16 de setembro de 2019.

UNIVERSIDADE FEDERAL DE SERGIPE. Programa de Pós-Graduação em

Economia. São Cristóvão, 2019. Disponível em: <http://nupec.ufs.br/>. Acesso em: 16 de setembro de 2019.

UNIVERSIDADE ESTADUAL DO OESTE DO PARANÁ. Pós-Graduação Mestrado em Economia. Toledo, 2019. Disponível em:

<https://www5.unioeste.br/portalunioeste/pos/pge>. Acesso em: 17 de setembro de 2019.

UNIVERSIDADE ESTADUAL DO RIO GRANDE DO NORTE. Programa de PósGraduação em Economia. Mossoró, 2019. Disponível em:

$<$ http://propeg.uern.br/ppe/default.asp?item=ppe-noticias>. Acesso em: 12 de setembro de 2019.

UNIVERSIDADE FEDERAL DE GOIÁS. Programa de Pós-Graduação em Economia. Goiânia, 2019. Disponível em: <https://ppe.face.ufg.br/>. Acesso em: 16 de setembro de 2019.

UNIVERSIDADE ESTADUAL DE CAMPINAS. Pós-graduação do Instituto de Economia - UNICAMP. Campinas, 2019. Disponível em:

<http://www.eco.unicamp.br/index.php/ensino/pos-graduacao>. Acesso em: 17 de setembro de 2019.

UNIVERSIDADE ESTADUAL DE CAMPINAS. Pós-graduação do Instituto de Economia - UNICAMP. Campinas, 2019. Disponível em: <http://www.eco.unicamp.br/index.php/ensino/pos-graduacao>. Acesso em: 17 de setembro de 2019.

UNIVERSIDADE FEDERAL DO RIO GRANDE DO SUL. Programa de Pós-Graduação em Economia. Mestrado Desenvolvimento. Porto Alegre, 2021. Disponível em: <https://www.ufrgs.br/ppge/mestrado-e-doutorado/mestrado/mestrado-desenvolvimento/>. Acesso em: 18 de março 2021.

UNIVERSIDADE FEDERAL DO RIO GRANDE DO SUL. Programa de Pós-Graduação em Economia. Mestrado Aplicada. Porto Alegre, 2021. Disponível em:

<https://www.ufrgs.br/ppge/mestrado-e-doutorado/mestrado/mestrado-aplicada/>. Acesso em: 18 de março 2021.

UNIVERSIDADE FEDERAL DE MINAS GERAIS. Faculdade de Ciências Econômicas. Belo Horizonte, 2019. Disponível em: <https://www.cedeplar.ufmg.br/>. Acesso em: 16 de setembro de 2019. 
UNIVERSIDADE FEDERAL DO PARÁ. Programa de Pós-Graduação em Economia. Belém, 2019. Disponível em: <http://ppge.propesp.ufpa.br/index.php/br/>. Acesso em: 16 de setembro de 2019.

UNIVERSIDADE FEDERAL DE SANTA MARIA. Programa de Pós-Graduação em Economia e Desenvolvimento. Santa Maria, 2019. Disponível em: <http://www.ufsm.br/ppged>. Acesso em: 17 de setembro de 2019.

UNIVERSIDADE FEDERAL DO PARANÁ. Todas as disciplinas. Curitiba, 2019. Disponível em: <http://www.prppg.ufpr.br/site/ppgde/todas-as-disciplinas/>. Acesso em: 16 de setembro de 2019.

UNIVERSIDADE FEDERAL DE VIÇOSA. Pós-Graduação em Economia Aplicada. Viçosa, 2019. Disponível em: <http://www.economia-aplicada.ufv.br/>. Acesso em: 18 de março de 2021.

UNISINOS. Mestrado e Doutorado em Economia. Porto Alegre, 2019. Disponível em: <http://www.unisinos.br/mestrado-e-doutorado/economia/presencial/porto-alegre>. Acesso em: 17 de setembro de 2019.

UNIVERSIDADE ESTADUAL DO RIO DE JANEIRO. Programa de Pós-Graduação em Ciências Econômicas. Rio de Janeiro, 2019. Disponível em:

<https://sites.google.com/view/ppgce-uerj>. Acesso em: 12 de setembro de 2019.

UNIVERSIDADE FEDERAL DO RIO GRANDE DO NORTE. Programa de PósGraduação em Economia. Natal, 2019. Disponível em:

<http://www.posgraduacao.ufrn.br/ppeco>. Acesso em: 16 de setembro de 2019.

UNIVERSIDADE FEDERAL DE PELOTAS. Programa de Pós-Graduação em

Organizações e Mercados. Pelotas, 2019. Disponível em:

<https://wp.ufpel.edu.br/ppgom/>. Acesso em: 16 de setembro de 2019.

PONTIFÍCIA UNIVERSIDADE CATÓLICA. Grade curricular. Rio de Janeiro, 2019. Disponível em: <http://www.puc-rio.br/ensinopesq/ccpg/progeco.html\#ementas>. Acesso em: 12 de setembro de 2019.

UNIVERSIDADE ESTADUAL DE PONTA GROSSA. Programa de Pós-Graduação em Economia. Ponta Grossa, 2019. Disponível em: <https://www3.uepg.br/ppgeco/>. Acesso em: 12 de setembro de 2019.

UNIVERSIDADE FEDERAL DE SÃO CARLOS. Programa de Pós-Graduação em

Economia. UFSCAR, 2021. Disponível em: <http://www.ppgec.ufscar.br/>. Acesso em: 28 de maio de 2019.

UNIVERSIDADE FEDERAL DE PELOTAS. Programa de Pós-Graduação em Organizações e Mercados. Pelotas, 2019. Disponível em: <https://wp.ufpel.edu.br/ppgom/>. Acesso em: 16 de setembro de 2019. 
UNIVERSIDADE FEDERAL DA INTEGRAÇÃO LATINO-AMERICANA. MESTRADO EM ECONOMIA (PPGE). Foz do Iguaçu, 2021. Disponível em:

$<$ https://portal.unila.edu.br/mestrado/economia>. Acesso em: 18 de março de 2021.

UNIVERSIDADE FEDERAL DO MATO GROSSO. Mestrado em Economia. Boa

Esperança, 2021. Disponível em: <https://www1.ufmt.br/ufmt/un/adr>. Acesso em: 18 de março de 2021.

UNIVERSIDADE FEDERAL DO MARANHÃO. PROGRAMA DE PÓS-GRADUAÇÃO EM DESENVOLVIMENTO SOCIOECONOMICO. São Luís, 2021. Disponível em: < https://sigaa.ufma.br/sigaa/public/programa/apresentacao_stricto.jsf?lc=pt_BR\&idProgram $a=1116>$. Acesso em: 18 de março de 2021.

UNIVERSIDADE FEDERAL RURAL DO RIO DE JANEIRO. PÓS-GRADUAÇÃO EM ECONOMIA REGIONAL E DESENVOLVIMENTO. Seropédica, 2021. Disponível em: <http://cursos.ufrrj.br/posgraduacao/ppger/>. Acesso em: 18 de março de 2021. 